\title{
Cell identity and sexual development in Cryptococcus neoformans are controlled by the mating-type-specific homeodomain protein Sxi1
}

\author{
Christina M. Hull, ${ }^{1}$ Robert C. Davidson, ${ }^{1,3}$ and Joseph Heitman ${ }^{1,2,4}$ \\ ${ }^{1}$ Department of Molecular Genetics and Microbiology, ${ }^{2}$ Howard Hughes Medical Institute, Duke University Medical Center, \\ Durham, North Carolina 27710, USA
}

Virulence in the human fungal pathogen Cryptococcus neoformans is associated with the $\alpha$ mating type. Studies to identify the properties of $\alpha$ cells that enhance pathogenesis have led to the identification of a mating-type locus of unusually large size and distinct architecture. Here, we demonstrate that the previously identified MAT $\alpha$ components are insufficient to regulate sexual differentiation, and we identify a novel $\alpha$-specific regulator, SXI1 $\alpha$. Our data show that SXI1 $\alpha$ establishes $\alpha$ cell identity and controls progression through the sexual cycle, and we discover that ectopic expression of $S X I 1 \alpha$ in a cells is sufficient to drive a/ $\alpha$ sexual development. SXI1 is the first example of a key regulator of cell identity and sexual differentiation in C. neoformans, and its identification and characterization lead to a new model of how cell fate and the sexual cycle are controlled in $C$. neoformans.

[Keywords: Basidiomycete; fungal pathogenesis; gene regulation; sex determination; mating-type locus; virulence]

Received September 12, 2002; revised version accepted October 9, 2002.

A fundamental question for organisms with different cell types is how unique cell identities are established and maintained. Sexual organisms from algae to mammals have evolved mechanisms that direct cells of different types to adopt unique sexual identities. Two common mechanisms govern cell identity: those based on sensing ploidy or dosage and those based on expression of a sexdetermining gene (Capel 1998). Dosage-dependent regulation establishes sexual identity in both flies and worms (Parkhurst and Meneely 1994). Although the molecular mechanisms by which dosage dictates cell fate differ, the principle is the same; $\mathrm{X}$ animals develop into males, whereas XX animals develop into females. By sensing the ratio of $\mathrm{X}$ chromosomes to autosomes, these organisms initiate different developmental programs that result in opposing sexual identities.

On the other hand, sexual differentiation in mice and humans is regulated by the presence of a sex-determining gene (Haqq and Donahoe 1998). In this case, the Sry

\footnotetext{
${ }^{3}$ Present address: Glycofi Inc., Thayer School of Engineering, Dartmouth College, Hanover, NH 03755, USA.

${ }^{4}$ Corresponding author.

E-MAIL heitm001@duke.edu; FAX (919) 684-5458.

Article and publication are at http://www.genesdev.org/cgi/doi/10.1101/ gad.1041402.
}

gene on the $\mathrm{Y}$ chromosome designates maleness and determines the fate of the organism; XX individuals develop into females, whereas XY individuals develop into males. This mechanism appears to be an ancient one because even the single-celled, green algae Chlamydomonas reinhardtii uses a differentially expressed gene to control cell identity. In this case, the Gsp1 homeodomain protein controls sexual cycle progression by triggering a change from gamete to zygote cell type (Zhao et al. 2001). The conservation of these mechanisms illustrates the importance of sexual identity and cell fate determination in both uni- and multicellular organisms.

Unlike mammals, most single-celled eukaryotes do not have sex chromosomes dedicated to maintaining cell identity, but they do contain a specialized region of the genome that differs between cell types. This region, called the mating-type (MAT) locus, has been studied extensively in fungi. Genes located in the MAT locus control fungal mating, and different mating types contain dissimilar information at this locus. That is, MAT loci differ from most of the genome because they contain information that is not the same between homologous chromosomes (Coppin et al. 1997; Casselton and Olesnicky 1998; Turgeon 1998). In a typical fungus, one haploid mating type contains genes encoding a information, and the other contains genes encoding $\alpha$ informa- 
tion. In the diploid cell that forms after mating, homologous chromosomes contain a region of nonhomologous sequence (a situation that is reminiscent of the $\mathrm{X}$ and $\mathrm{Y}$ sex chromosomes of multicellular eukaryotes). This arrangement of the MAT locus allows cells of opposing mating types to respond differentially to each other and to their environments.

How the MAT locus determines cell fate has been elucidated in Saccharomyces cerevisiae (Herskowitz et al. 1992). This budding yeast has two mating types, a and $\alpha$, which can mate to form a third cell type, the a $/ \alpha$ diploid cell. Changes in gene expression in the different cell types control their sexual identities. In $\alpha$ cells, the $\alpha 1$ and $\alpha 2$ proteins are expressed from MAT $\alpha$ and are responsible for activating $\alpha$-specific genes and repressing a-specific genes, respectively. In a cells, the a 1 protein is expressed from MATa and has no known function in a cells. When a and $\alpha$ cells mate to form a diploid cell, a1 and $\alpha 2$ interact to form a new regulatory activity in the cell that is responsible for repressing haploid-specific genes. This repression prevents diploid cells from mating but allows them to undergo meiosis and sporulation in response to specific environmental signals. Much like sexual identity determinants in multicellular organisms (such as SRY), these cell-type-specific proteins establish and maintain cell identity in this single-celled organism (Johnson 1995).

Cell identity is also important in other, less wellknown fungi. Like $S$. cerevisiae, the fungal pathogen Cryptococcus neoformans is amenable to genetic study because it is a haploid organism with two mating types (a and $\alpha$ ) that engage in a sexual cycle that can be reproduced and manipulated in the laboratory (Alspaugh et al. 2000). What distinguishes $C$. neoformans from $S$. cerevisiae and most other fungi, however, is its ability to cause disease in humans. C. neoformans infects primarily immunosuppressed individuals, including AIDS patients, transplant recipients, and patients undergoing chemotherapy (Casadevall and Perfect 1998). It appears that the haploid spores of $C$. neoformans lodge in the lung, where they can disseminate and lead to life-threatening cryptococcal meningitis.

Several virulence factors that contribute to the success of $C$. neoformans as a pathogen have been identified, and one of these is mating type (Casadevall and Perfect 1998). More than $95 \%$ of all C. neoformans isolates are $M A T \alpha$, and in murine experiments $\alpha$ cells have been shown to be more virulent than a cells (Kwon-Chung et al. 1992; Casadevall and Perfect 1998). It is clear that cell type plays an important role in $C$. neoformans virulence, but the exact mechanism by which it contributes remains to be determined. Thus, analyzing differences between the a and $\alpha$ cells of $C$. neoformans will prove useful in understanding the characteristics of the fungus required for virulence. It is likely that the important differences between these two cell types will be directly related to the genes in the MAT locus and their targets.

Mating information in the basidiomycete phylum of fungi to which $C$. neoformans belongs is generally found in two MAT loci, wherein one locus encodes phero- mones and pheromone receptors and the other locus encodes homeodomain transcriptional regulators that control mating genes (Kronstad and Staben 1997; Casselton and Olesnicky 1998). A MAT locus has been defined in the C. neoformans $\alpha$ cell type (Moore and Edman 1993; Karos et al. 2000), and it is distinct from any previously identified basidiomycete or other fungal MAT locus. When we began our work, MAT $\alpha$ was thought to encompass a single, $\sim 50-\mathrm{kb}$ region that contains 12 genes, most of which have not been found previously in fungal MAT loci. Interestingly, this single locus contains pheromones and pheromone receptors but no obvious homeodomain proteins; thus, it has been unclear how mating genes are controlled in C. neoformans. Recent work, however, has shown the MAT locus to be much larger than $\sim 50 \mathrm{~kb}$ and to contain more genes than previously thought (Lengeler et al. 2002).

The MAT locus controls three developmental pathways in the C. neoformans sexual cycle (Fig. 1). During the process of mating, the locus is important for sensing a mating partner, forming projections called conjugation tubes, and making subsequent filamentation and sporulation structures (Davidson et al. 2000; Lengeler et al. 2000). The process of diploid filamentation, in which diploid cells form filaments and sporulation structures in response to a decrease in temperature, is similarly controlled by MAT (Sia et al. 2000). Components of the $M A T$ locus are also responsible for regulating the process of filament and spore production in haploid cells known as haploid filamentation (Wickes et al. 1996). This process is specific to $\alpha$ cells, and several single gene deletions in MAT $\alpha$ abolish this haploid differentiation (Yue et al. 1999; Chang et al. 2000; Clarke et al. 2001). Recent data suggest, however, that this previously defined locus is not sufficient for carrying out all of the functions of the sexual cycle and that additional regulatory components outside of $M A T \alpha$ are required for specifying the $\alpha$ cell fate.

Here, we present the discovery and analysis of a $C$. neoformans sexual cycle regulator that does not reside within the previously identified $\sim 50-\mathrm{kb} M A T$ locus. Unexpectedly, we found that a deletion of the known $M A T \alpha$ allele did not abolish a $/ \alpha$ cell identity. This finding made it clear that additional components control the sexual cycle. To test the hypothesis that cell ploidy could control sexual development, we created homozygous a/a and $\alpha / \alpha$ diploid strains of $C$. neoformans and tested their ability to differentiate. These experiments proved that ploidy alone is not sufficient for $\mathbf{a} / \alpha$ diploid behavior and that both a and $\alpha$ information are required for proper sexual development. This result prompted us to use a bioinformatics approach to identify genes of interest and led to the discovery of a gene encoding an additional regulatory factor, $S X I 1 \alpha$, a homeodomain protein found

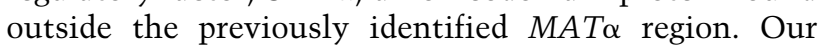
analysis of sxi1 $\alpha$ deletion strains revealed a crucial role for this gene in establishing a/ $\alpha$ cell identity. Strikingly, we also discovered that ectopic expression of $S X I 1 \alpha$ in haploid a cells caused them to adopt an a/ $\alpha$ cell fate. This finding, along with expression data, reveals that this 
Figure 1. The Cryptococcus neoformans life cycle. There are three developmental pathways for C. neoformans cells. The first pathway, known as mating (A), begins when two haploid cells of opposite mating types fuse at $25^{\circ} \mathrm{C}$. The haploid cells fuse and grow as filaments with distinct nuclei (dikaryons) and special clamp cells that are fused to the filaments. In response to unknown signals, the dikaryon produces a specialized sporulation structure known as a basidium. It is in the basidium that nuclear fusion and meiosis take place. Many rounds of duplication and mitosis lead to the production of haploid a and $\alpha$ spore products that extend in long chains from the basidial head. The second developmental pathway, known as diploid filamentation (B), occurs when cells of opposite mating types fuse and are maintained at $37^{\circ} \mathrm{C}$. In this case, the haploid cells and their nuclei fuse to create a yeastform, diploid cell that grows as a yeast at $37^{\circ} \mathrm{C}$. In response to a decrease in temperature $\left(25^{\circ} \mathrm{C}\right)$, this a/ $\alpha$ diploid differentiates to form monokaryotic filaments with unfused clamp cells, basidia, and haploid a and $\alpha$ spores that

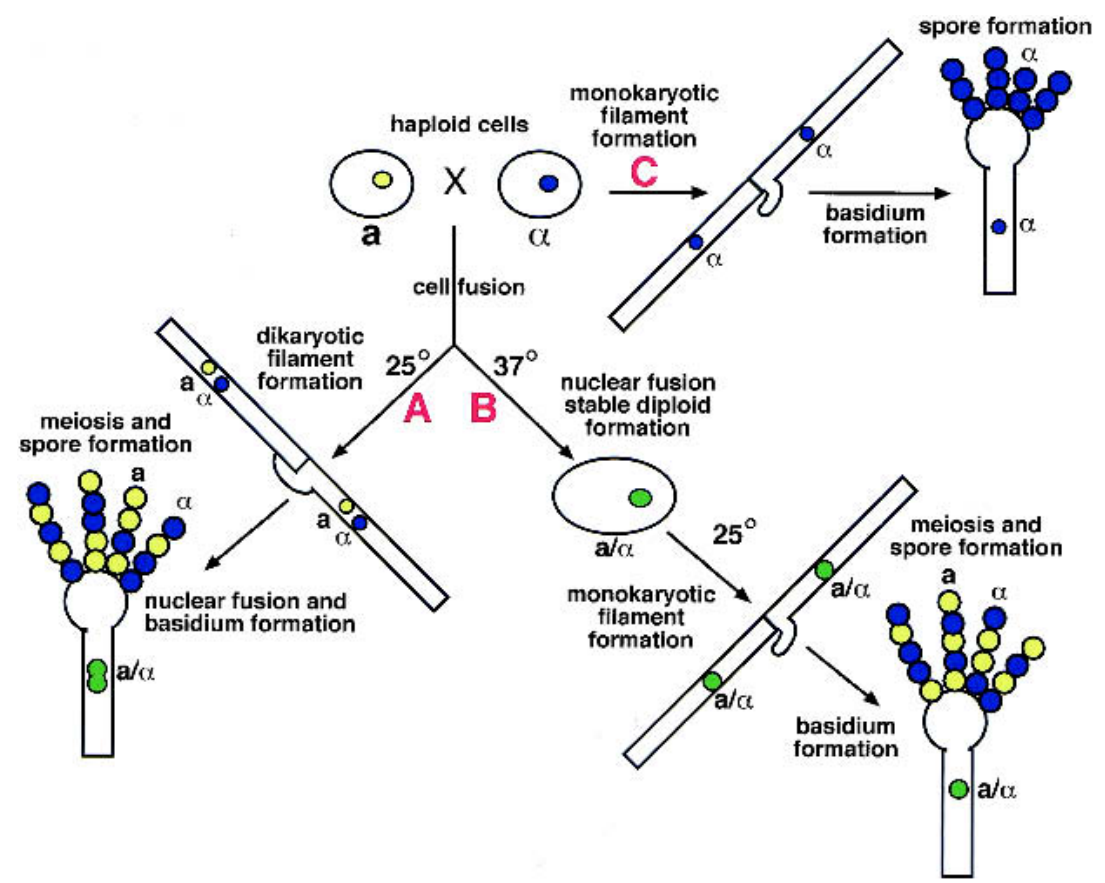
are indistinguishable from those produced dur-

ing mating. The third possible fate occurs in cells of the $\alpha$ mating type. This pathway is known as haploid fruiting $(\mathrm{C})$ and occurs when $\alpha$ cells are grown under nutrient-limited, desiccating conditions. In this pathway, haploid $\alpha$ cells form monokaryotic filaments with unfused clamp cells, basidia, and haploid $\alpha$ spores. In each case, the resulting spores are competent to germinate and grow as vegetative haploid cells or initiate one of the three developmental pathways (A-C).

gene is a key transcriptional regulator responsible for controlling the $C$. neoformans sexual cycle. This discovery makes it clear that although $C$. neoformans is unique among fungi in its MAT locus architecture, it has maintained a conserved homeodomain regulator that both establishes cell identity and drives sexual differentiation.

\section{Results}

The previously identified MAT $\alpha$ allele is insufficient to specify the a cell type

To evaluate the role of MAT $\alpha$ in specifying the $\alpha$ cell type, we created a deletion of the entire previously identified $M A T \alpha$ allele (Fig. 2A). Using a polymerase chain reaction $(\mathrm{PCR})$-based deletion strategy, we attempted to delete the entire $48.8-\mathrm{kb}$ region of the known $M A T \alpha$ region in an $\alpha$ haploid strain. This effort to disrupt the entire $\alpha$ locus failed (0/300 $\mathrm{Ura}^{+}$transformants) presumably because of an essential gene(s) in the locus; however, in the first use of a stable $C$. neoformans a $/ \alpha$ diploid strain for gene disruption, we deleted the entire $M A T$ region on the $\alpha$ chromosome. MATa/mat $\alpha$ deletion strains $(\mathbf{a} / \Delta)$ were confirmed by PCR analysis (Fig. 2B) and by Southern blot analysis (Fig. 2C) and shown to contain precise deletions of the MAT $\alpha$ region. As represented in Figure 1, pathway B, a/ $\alpha$ diploid strains of $C$. neoformans undergo a temperature-dependent developmental process referred to as diploid filamentation (Fig. 2D, top panel; Sia et al. 2000). We predicted that the deletion of $\alpha$ information from a/ $\alpha$ cells would lead to a loss of $\mathbf{a} / \alpha$ identity and result in a cell behavior (i.e., the diploid strains would no longer be self-filamentous). Surprisingly, the $\mathbf{a} / \Delta$ strain retained its a/ $\alpha$ identity and remained competent to undergo diploid filamentation and produce viable haploid spores (Fig. 2D, middle panel). These findings suggested that the deleted $\alpha$ information was not required for diploid filamentation and that some other region of the genome was responsible for establishing a $/ \alpha$ cell identity. This idea was further substantiated by the finding that a presumptive $2 \mathrm{n}-1$ diploid strain $(\mathbf{a} / 0$; in which the chromosome containing the URA5marked mat $\alpha$ deletion had been selected against by growth on 5-FOA medium) no longer retains its a/ $\alpha$ cell identity and behaves instead like an a cell (exhibiting no filamentation behavior; Fig. 2D, bottom panel). The mating type of this strain was also confirmed in assays in which the a/0 strain mated well with an $\alpha$ tester strain but showed no mating with an equivalent a tester strain (data not shown). Thus, $\alpha$ identity was abolished by loss of the entire $M A T \alpha$-containing chromosome but not by loss of the known $M A T \alpha$ region alone.

The surprising behavior of the a/ $\Delta$ strain lacking the entire known $M A T \alpha$ allele led us to consider two possible hypotheses to explain how the process of filamentation could be regulated. In the first hypothesis, filamentation of diploid cells could be regulated in a ploidyor dosage-dependent manner. a/ $\alpha$ diploids would filament because the ploidy-sensing mechanism detects the diploid state and activates filamentation independent of MAT $\alpha$. The a/0 strain would fail to filament be- 

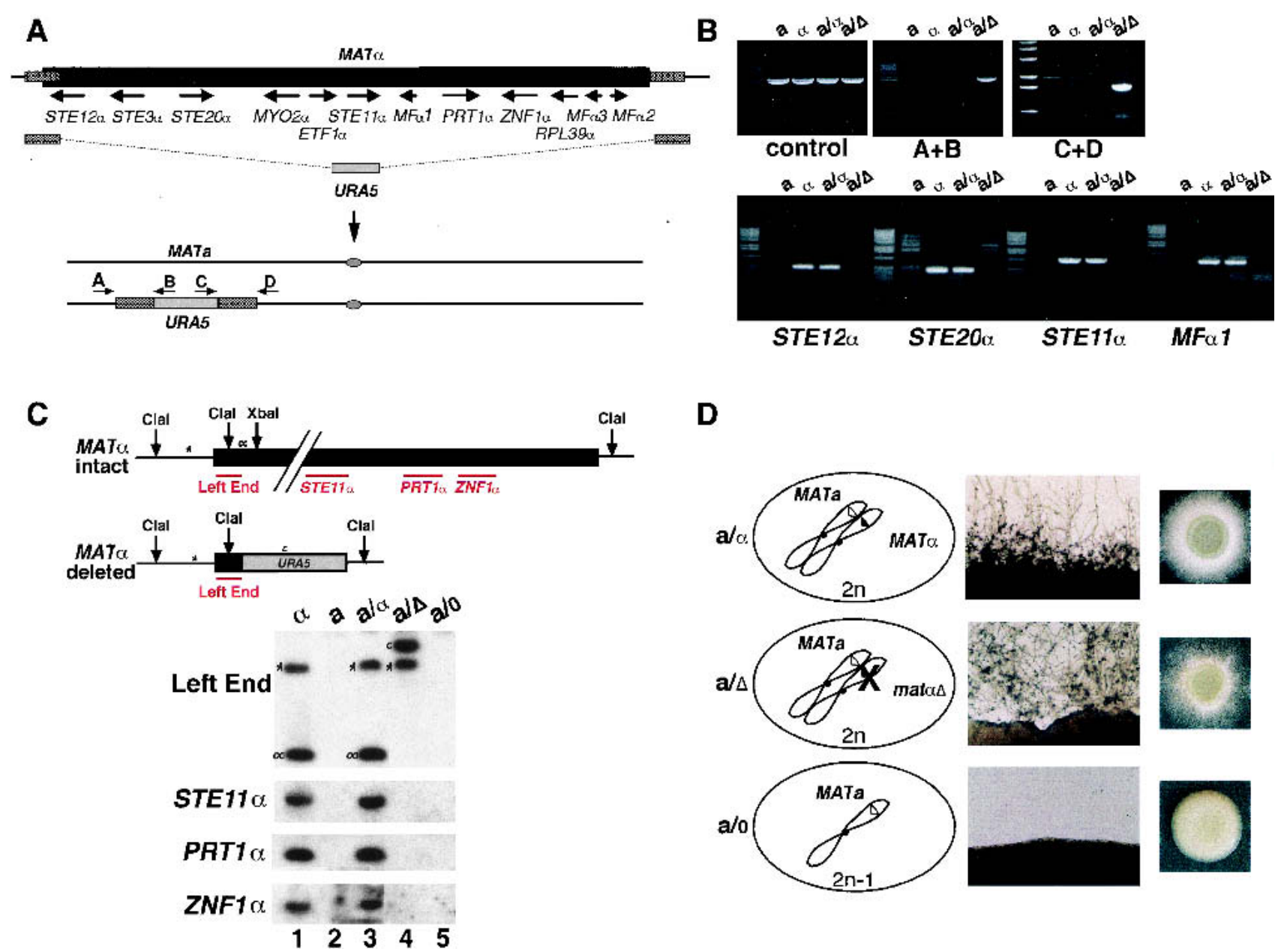

Figure 2. Deletion of $M A T \alpha$ does not abolish a/ $\alpha$ cell identity. (A) A schematic diagram of the MAT $\alpha$ allele (black box) shows the arrangements of genes in the locus, with arrows indicating the directions of transcription. Hatched boxes indicate the regions of DNA used as sites for recombination in a PCR-generated, URA5 deletion construct. A schematic of the a and $\alpha$ chromosomes shows the predicted mat $\alpha$ deletion configuration, and arrows designated A-D represent primers used in PCR of $B$. $(B)$ PCR results confirm the presence of the proper sequences at the junctions of the mat $\alpha$ deletion and the absence of genes located in MAT $\alpha$. Each set of reactions shows the results of PCR with different primer pairs carried out on genomic DNA from wild-type a and $\alpha$ strains, a wild-type a/ $\alpha$ diploid strain, and a diploid mat $\alpha$ deletion strain $(\mathbf{a} / \Delta)$. The first lane in each set of reactions contains size standards. $(C)$ Southern blot analysis confirms the mat $\alpha$ deletion. Genomic DNA from $\alpha$ and a wild-type strains (lanes 1,2), a wild-type a/ $\alpha$ diploid strain (lane 3), a $M A T \mathbf{a} /$ mat $\alpha$ strain $(\mathbf{a} / \Delta$, lane 4$)$, and a strain presumably missing the $M A T \alpha$ chromosome $(\mathbf{a} / 0$, lane 5$)$ was restriction-digested. A probe to the left end of the locus hybridized to two fragments in the expected strains. Symbols to the left of the Southern bands correspond to symbols in the accompanying schematic drawing of the intact and deleted MAT $\alpha$ alleles. $(D)$ The panels from left to right show the configuration of the MAT locus in each strain, a magnified view of the filaments formed during sexual differentiation, and a macroscopic view of the filaments on solid agar medium. The top row shows the pattern for wild-type a/ $\alpha$ diploid cells, the middle row shows the MATa/mat $\alpha$ strain $(\mathbf{a} / \Delta)$, and the bottom row shows the MAT $\alpha$ chromosome loss strain $(\mathbf{a} / 0)$. Note: Analysis of spores from the a/ $\Delta$ strain yielded only MATa ura5 meiotic segregants, proving the presence of an essential gene or genes in MAT $\alpha$.

cause it is not fully diploid, or the dose of a specific gene product from the $M A T$ chromosome is diminished. In the second hypothesis, the process of filamentation in diploid cells could be regulated in a gene-dependent manner. Specific genes from a and $\alpha$ cells could function together to combinatorially promote filamentation, and the loss of either set of genes would result in a loss of filamentation. In the a $/ \Delta$ strain the $\alpha$ gene(s) is still intact, so the strain filaments, but in the presumptive chromosome loss strain $(\mathbf{a} / 0)$, the $\alpha$ gene(s) has been lost, and with it, the ability to filament.

\section{Diploid filamentation is dependent on the presence of information from both $\boldsymbol{a}$ and $\alpha$ cells}

We distinguished between ploidy-dependent and genedependent regulation by constructing a/a and $\alpha / \alpha$ diploids and testing their filamentation behavior. We predicted that if ploidy were an inducer of filamentation independent of a- and $\alpha$-specific signals, then homozygous $\mathbf{a} / \mathbf{a}$ and $\alpha / \alpha$ diploid strains would be self-filamentous. Homozygous diploid strains of other fungi have been created using a variety of means from UV irradia- 
Hull et al.

tion (Banuett and Herskowitz 1989) to forced gene conversion in a/ $\alpha$ diploids (Hartwell 1980), but we were able to create these strains in $C$. neoformans by using a novel approach to take advantage of the propensity of $C$. neoformans for promiscuous fusion. Auxotrophic strains of the same mating type (e.g., a ura5 lys1 and a ade2 lys2) were mixed in a mating reaction in the presence of a multiply marked, auxotrophic opposite mating partner (e.g., $\alpha$ ura5 ade2 lys1). These mixes were then subjected to selective growth conditions in which only $\mathbf{a} / \mathbf{a}$ or $\alpha / \alpha$ diploid strains (but not $\mathbf{a} / \alpha$ ) strains could grow (e.g., medium lacking adenine, uracil, and lysine). At a low frequency, strains of the same mating type engaged in promiscuous fusion events in the presence of the opposite mating type (Fig. 3A). The resulting prototrophic strains were recovered and subjected to fluorescence-activated cell scanning (FACS) analysis that confirmed a DNA content consistent with diploidy (Fig. 3B). The prototrophic strains were also shown by PCR with mating-typespecific primers to contain only a or $\alpha$ information (Fig. $3 \mathrm{C})$. These confirmed $\mathbf{a} / \mathbf{a}$ and $\alpha / \alpha$ homozygous diploid strains behaved like their haploid counterparts in mating (data not shown), haploid fruiting (data not shown), and diploid filamentation. Neither of the homozygous diploid strains exhibited filamentous growth on V8 medium after $48 \mathrm{~h}$ at $25^{\circ} \mathrm{C}$, whereas an a/ $\alpha$ heterozygous control strain filamented well (Fig. 3D). Because diploid cells that were $\mathbf{a} / \mathbf{a}$ or $\alpha / \alpha$ did not undergo diploid filamenta-
A
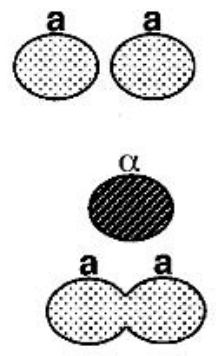

or

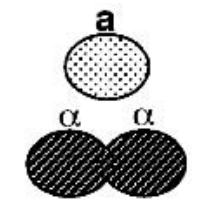

C

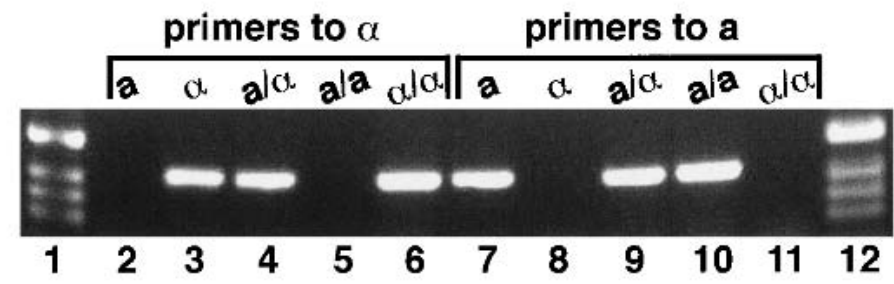

D

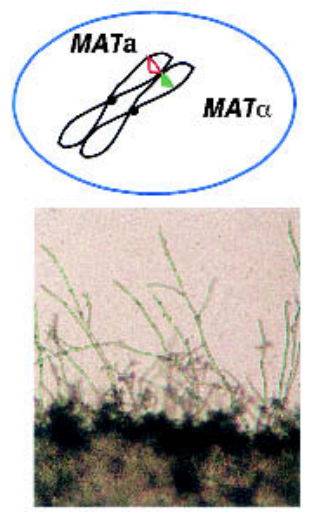

$\mathbf{a} / \alpha$

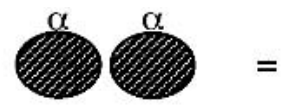

= promiscuous fusion

between same cell types

no fusion

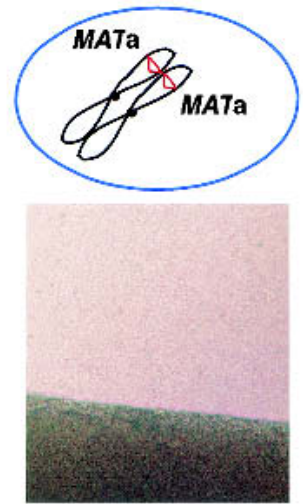

$\mathbf{a} / \mathbf{a}$

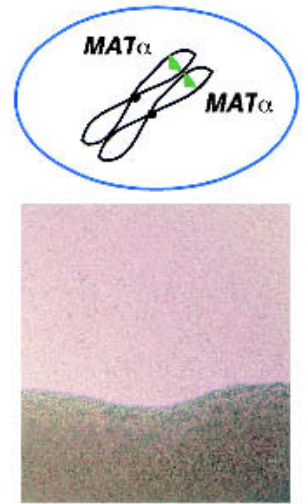

$\alpha / \alpha$
B
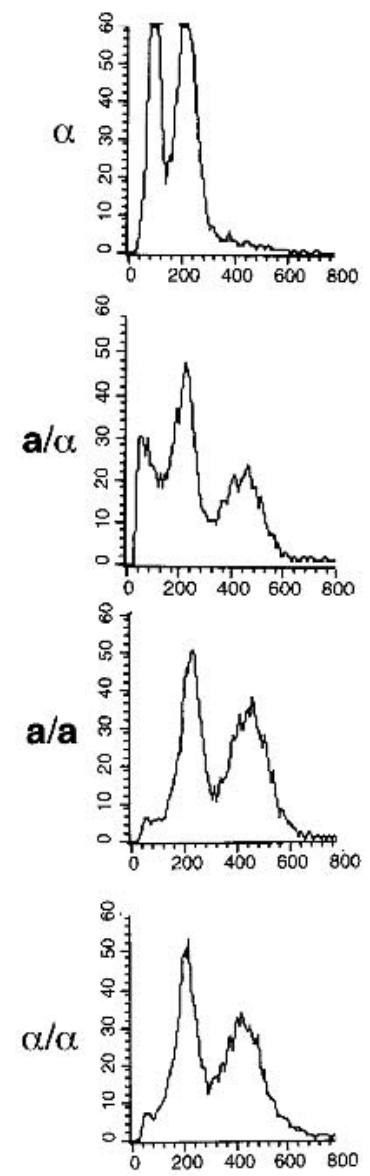

Figure 3. Ploidy alone does not regulate diploid filamentation. (A) Homozygous diploid strains of C. neoformans were created by incubating strains of the same mating type in the presence of a helper strain as a pheromone donor (see Materials and Methods for details). Shaded ovals represent a cells, and hatched ovals represent $\alpha$ cells. (B) FACS analysis of prototrophic products is consistent with diploidy. From top to bottom, panels show the FACS profile for an $\alpha$ haploid, an a/ $\alpha$ diploid, an a/a diploid, and an $\alpha / \alpha$ diploid. (C) PCR confirms the presence of only a or $\alpha$ information in homozygous diploid strains. Genomic DNA from five different strains (including those used in FACS analysis) was used in a PCR as designated. (Lanes 2-6) $\alpha$-Specific primers to STE20 $\alpha$. (Lanes 7-11) a-Specific primers to STE2Oa. (D) Filamentation of diploid strains is not dependent on ploidy alone. Each panel shows a schematic representation of MAT and the results of a self-filamentation assay. (Left to right) $\mathbf{a} / \alpha, \mathbf{a} / \mathbf{a}, \alpha / \alpha$. 
tion, we conclude that diploidy alone is not sufficient to activate filamentation.

This finding rules out a ploidy-only model of diploid regulation, and indicates that both a and $\alpha$ information are necessary for diploid sporulation. This result is consistent with the hypothesis that a-specific and $\alpha$-specific genes are responsible for regulating the filamentation process through the specification of cell type. Under this model, the ability of the $\mathbf{a} / \Delta$ strain to filament makes it clear that the required information for filamentation from $\alpha$ cells is not located entirely within the previously defined MAT $\alpha$ allele. In addition, the behavior of the a/0 strain indicates that at least one of the required components resides in a different location on the same chromosome as $M A T \alpha$.

\section{Identification of an $\alpha$-specific homeodomain protein}

These results suggested strongly that additional regulatory factors not located in MAT $\alpha$ are responsible for mediating diploid filamentation. Based on the structures of other fungal MAT loci (Casselton and Olesnicky 1998), and given that the previously defined locus in C. neoformans contained pheromones and a pheromone receptor but no clear DNA-binding proteins (Karos et al. 2000), it was logical to propose that another region of the $M A T \alpha-$ containing chromosome encoded DNA-binding proteins. Using sequences from the Candida albicans $\alpha 2$ homeodomain protein (Hull and Johnson 1999), we searched the Stanford C. neoformans genome sequence for similar proteins. Using the BLAST algorithm in con- junction with homeodomain structural data (Li et al. 1995; Altschul et al. 1997), six possible homeodomain proteins were identified, and each sequence was evaluated in two ways. First, Southern blot analysis of DNA from both a and $\alpha$ cells was performed using a probe to the sequence of interest. A chromosome blot was then probed to determine the chromosome location of the sequence. One of the six genes (now known as $S X I 1 \alpha$, for $\underline{\text { Sex }} \underline{\text { Inducer }} \underline{1 \alpha}$ ) was specific to $\alpha$ cells (Fig. 4A), and it was located on the MAT $\alpha$-containing chromosome (Fig. 4B). The other five homeodomain-containing sequences were not $\alpha$-specific (data not shown). In addition, PCR analysis of multiple a and $\alpha$ segregants showed that the $S X I 1 \alpha$ DNA sequence was found only in the $\alpha$ mating type after a genetic cross (Fig. 4C), confirming linkage to the $\alpha$ mating type.

Alignment of the predicted $S X I 1 \alpha$ homeodomain region with other homeodomain proteins reveals that many residues known to be important for DNA interactions are conserved (Fig. 5A). Sxil $\alpha$ contains an argininerich region in the predicted helix 3 , consistent with other homeodomain proteins. Several key residues within this predicted helix are conserved. In particular, asparagine51 , which is invariant among almost all homeodomain proteins (Burglin 1997), and glutamine-44, arginine-53, arginine-54, and arginine-55, which are important for base contacts during DNA binding by a1- $\alpha 2$ (Li et al. 1995), are all conserved. Other important base contact residues are not strictly conserved in Sxil $\alpha$ (i.e., tryptophan-48), but variation among homeodomains is not unusual, and the overall similarity of Sxil $\alpha$ with other homeodomains is high enough to construct a phylogenetic
A

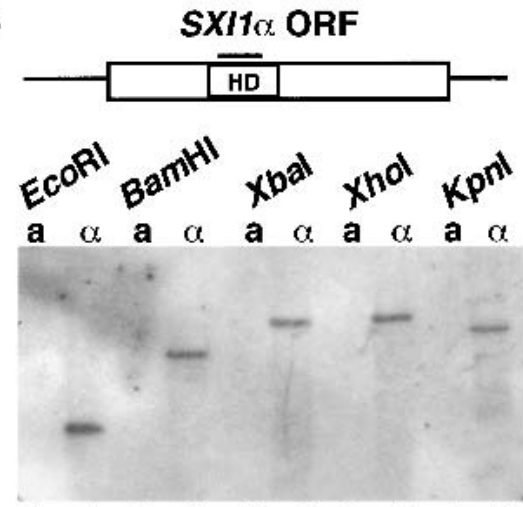

$\begin{array}{llllllllll}1 & 2 & 3 & 4 & 5 & 6 & 7 & 8 & 9 & 10\end{array}$
B

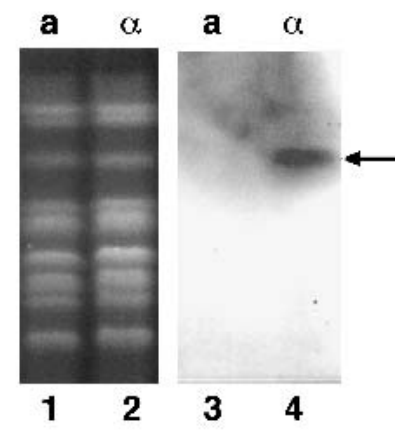

Figure 4. $S X I 1 \alpha$ is an $\alpha$-specific gene. $(A)$ The open box represents the $S X I 1 \alpha$ open reading frame, and the box within represents the predicted homeodomain (HD). The bar above HD represents the probe used in Southern hybridization. A Southern blot was generated using DNA from wild-type a and $\alpha$ cells digested with several different restriction enzymes, as indicated. $(B$, lanes 1,2) An ethidium bromide-stained gel containing the $C$. neoformans chromosomes from both a and $\alpha$ cells. The MAT locus is located on the third visible chromosome from the top. (Lanes 3,4) A chromoblot filter to which the homeodomain probe of $A$ has been hybridized; the arrow designates the $\alpha$-specific band corresponding to the third visible chromosome. (C) Genomic DNA from segregants of a genetic cross was subjected to PCR analysis using primers to the

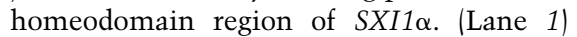
marker; (lanes 2,3) DNA from control a cells and $\alpha$ cells, respectively; (lanes 4-10) DNA from segregants that mate as a cells; (lanes 11-17) DNA from segregants that mate as $\alpha$ cells. Arrow A indicates the $S X I 1 \alpha$ PCR product. Arrow B indicates a control product generated with non-celltype-specific primers. 
Hull et al.
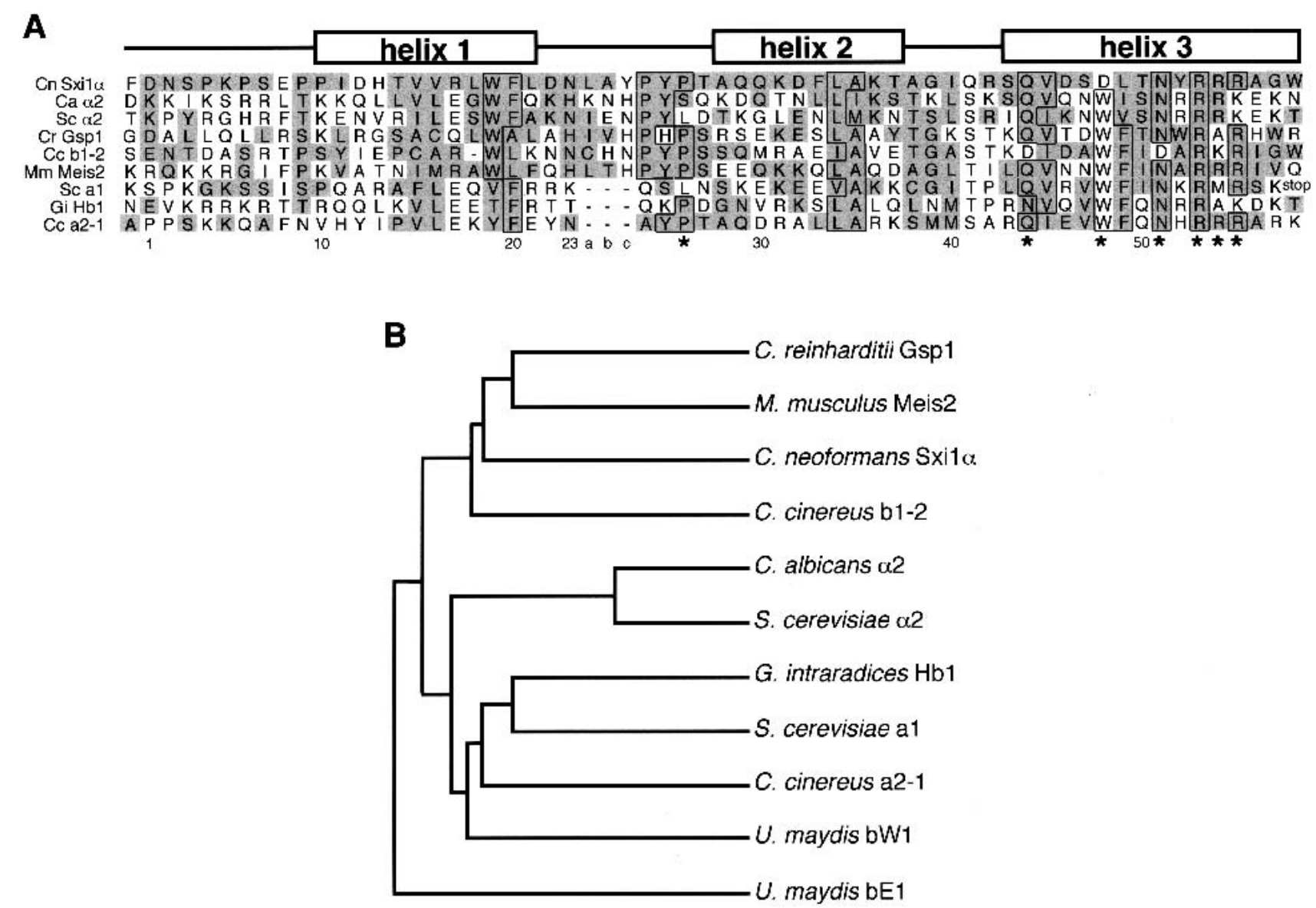

Figure 5. Sxil $\alpha$ is predicted to be a homeodomain protein. (A) The predicted homeodomain region of Sxil $\alpha$ is aligned with known homeodomains of other proteins, Ca (Candida albicans) $\alpha 2$, Sc (Saccharomyces cerevisiae) $\alpha 2$, Cr (Chlamydomonas reinhardtii) Gsp1, Cc (Coprinus cinereus) b1-2, Mm (Mus musculus) Meis-2, Sc a1, Gi (Glomus intraradices) Hb1, and Cc a2-1. A schematic representation of the homeodomain region showing the helices of a classic three-helix structure found in many homeodomains is above the sequences. Identical residues are outlined, and similar residues are highlighted in gray. Stars highlight key DNA-binding contacts. (B) Phylogenetic tree constructed using the homeodomain regions of the represented proteins. Proteins are the same as in $A$ with the exception of the Ustilago maydis proteins bW1 and bE1, which have been included in the tree.

tree. Of the fungal regulators, the Sxil $\alpha$ homeodomain protein is most closely related to a mating protein from Coprinus cinereus (b1-2), a distant but related member of the basidiomycete family of fungi (Fig. 5B).

\section{SXI1 $\alpha$ establishes cell identity in C. neoformans}

To assess what role this apparent homeodomain protein might play in the life cycle of $C$. neoformans, we created a sxi1 $\alpha$ deletion strain. Most of the predicted SXI1 $\alpha$ open reading frame, including the predicted homeodomain region, was deleted in both haploid and diploid cells using a PCR-based disruption strategy (Davidson et al. 2002). The resulting deletion strains were tested for their behavior in a series of phenotypic assays. We were most interested in determining what role $S X I 1 \alpha$ plays in regulating the $C$. neoformans sexual cycle, so haploid and diploid deletion strains were exposed to mating and filamentation conditions and evaluated for their ability to form spores. As shown in Figure 6A, mating in the sxi1 $\alpha$ deletion strain is severely impaired, as evidenced by diminished filament formation in the presence of an a mating partner (Fig. 6A, top, middle) compared with a wildtype $\alpha$-by-a cross (Fig. 6A, top, left). The few filaments that do form are grossly abnormal and fail to develop basidia or spores and are rapidly overgrown by the vegetative cell mass. This mating defect does not, however, stem from a defect in cell fusion between mating partners. Experiments in which prototrophs were selected in a cross with marked strains resulted in no decrease in prototroph formation when the sxi1 $\alpha$ deletion strain was mated to a cells (data not shown). In summary, Sxil $\alpha$ is dispensable for cell fusion but necessary for filament formation and development after cell fusion.

Experiments in a $/ \alpha$ diploids also support a role for Sxil $\alpha$ activity after cell fusion. Even though cell fusion has already occurred in $\mathbf{a} / \alpha$ cells and is therefore not required for diploid self-filamentation, diploid $\mathbf{a} / \alpha$ sxi1 $\alpha \Delta$ strains still fail to filament properly. As shown in Figure $6 \mathrm{~B}$, the $\mathrm{a} / \alpha$ sxi1 $\alpha$ deletion strain (Fig. $6 \mathrm{~B}$, top, 
A
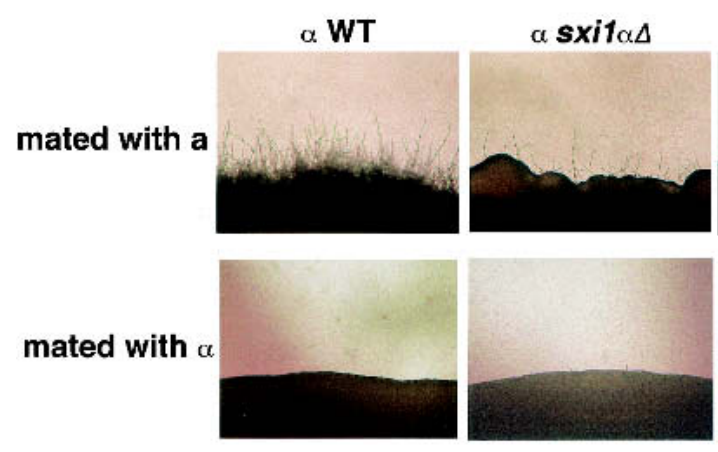

$\mathrm{a} / \Delta \mathrm{sxi1} \alpha \Delta$

B
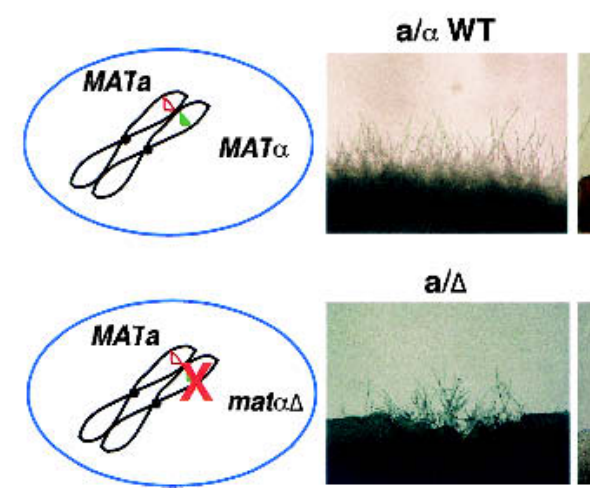

diploid

filamentation $a / \alpha W T$

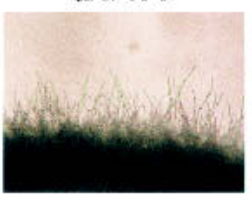

$a / \Delta$

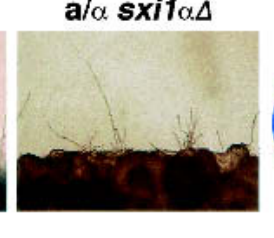

$\mathrm{a} / \Delta \mathrm{sxi1} \alpha \Delta$

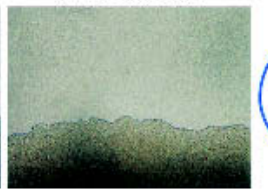

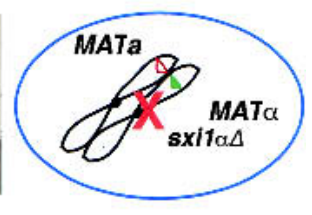

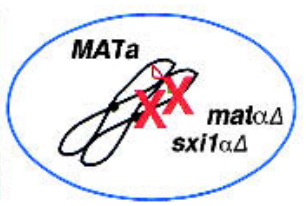

Figure 6. Sxil $\alpha$ is a key regulator of cell fate. (A) Panels show the filamentation results of a mating assay in which different strains were mixed and incubated under mating conditions. (Top panels, from left to right) The results of crosses between wild-type a cells and wild-type $\alpha$ cells, between wild-type a cells and the sxil $\alpha$ deletion strain, and between wild-type a cells and the sxila mat $\alpha$ double deletion strain. (Bottom panels, from left to right) The results of crosses between wild-type $\alpha$ cells, between wild-type $\alpha$ cells and the sxi1 $\alpha$ deletion strain, and between wildtype $\alpha$ cells and the sxi1 $\alpha$ mat $\alpha$ double deletion strain. (B) Panels show the results of diploid filamentation after several days under filamentation conditions, and schematic drawings show the configuration of the MAT locus for each strain tested. right) is severely compromised for filament formation compared with a wild-type a/ $\alpha$ strain (Fig. $6 \mathrm{~B}$, top left). In addition, the few filaments that do form are enlarged, arrested in development, and defective in basidia and spore production. Thus, Sxil $\alpha$ is important for diploid cells to progress through the sexual cycle. This is very different from the a/ $\Delta$ strain, in which filament formation is intact (although somewhat diminished), and the filaments that form produce normal basidia and spores (Fig. 6B, bottom, left).

To test the hypothesis that $S X I 1 \alpha$ is the "missing regulator" required for establishing $\alpha$ cell identity, $S X I 1 \alpha$ was deleted from the a/s strain to create a MATa/mat $\alpha \Delta$ $s x i 1 \alpha \Delta$ strain in which filament and spore formation were tested (Fig. 6B, bottom, right). In this strain, all filament formation is eliminated, indicating that this combination of mutations abolishes the sexual cycle. More importantly, this strain now has a changed cell identity. By deleting both $S X I 1 \alpha$ and the $\sim 50-\mathrm{kb} M A T \alpha$ region, the $\mathbf{a} / \alpha$ diploid cell identity has been changed to that of an a cell. In filamentation assays, the diploid cells with either the mat $\alpha$ deletion $(\mathbf{a} / \Delta)$ or the sxi1 $\alpha$ deletion $(\mathbf{a} / \alpha s x i 1 \alpha \Delta)$ are partially self-filamentous, and neither responds to a or $\alpha$ mating partners. However, the strain containing both deletions $(\mathbf{a} / \Delta s \times i 1 \alpha \Delta)$ mates as an a cell. As shown in Figure 6A (right panels), the double deletion strain forms mating filaments in the presence of an $\alpha$ mating partner but does not respond to an a partner.
Deletion of both the known MAT $\alpha$ region and the $S X I 1 \alpha$ gene resulted in the phenotype previously anticipated for a MATa/mat $\alpha$ deletion strain, suggesting that $S X I 1 \alpha$ is either part of a second, previously unidentified MAT locus in C. neoformans or that the known MAT $\alpha$ allele is much larger than previously suspected and, in fact, contains $S X I 1 \alpha$. Recent studies from our laboratory presented elsewhere prove the latter hypothesis to be correct, and $S X I 1 \alpha$ is located $\sim 55 \mathrm{~kb}$ away from the originally identified $M A T \alpha$ region in a single, contiguous $M A T \alpha$ allele with 20 other genes of diverse function (Lengeler et al. 2002). No other DNA-binding proteins resembling those of other fungal $M A T$ loci are present in $M A T \alpha$, but it is clear that $S X I 1 \alpha$ and a gene (or genes) located in the $\sim 50-\mathrm{kb}$ deletion are necessary to maintain $\alpha$ cell identity. Deletion of either one alone results in diminished $\alpha$ behavior but does not abolish $\alpha$ identity. Deletion of both $S X I 1 \alpha$ and a gene(s) in the MAT $\alpha$ region results in a complete loss of $\alpha$ identity in a/ $\alpha$ cells, consistent with having removed all of the genes responsible for designating the $\alpha$ cell fate.

\section{Ectopic expression of SXI1 $\alpha$ in a cells results in $\mathbf{a} / \alpha$ cell development}

Having established that Sxil $\alpha$ was a necessary contributor to $\alpha$ identity, we then tested whether Sxil $\alpha$ is sufficient to confer $\alpha$ identity by expressing Sxil $\alpha$ in haploid 
a cells. Under the control of its own promoter, $S X I 1 \alpha$ was not expressed in a cells (data not shown); therefore, $S X I 1 \alpha$ was placed under the control of a strong, constitutive promoter (glyceraldehyde-3-phosphate dehydrogenase), and the expression plasmid (GPD1-SXI1 $\alpha$ ) was transformed into wild-type $\alpha$ cells, sxi1 $\alpha$ deletion cells, and wild-type a cells. Transformants were then tested for the ability to form filaments alone and in test crosses. As summarized in Figure 7A, sxi1 $\alpha$ deletion cells transformed with GPD1-SXI1 $\alpha$ behaved like wild-type $\alpha$ cells. That is, they were not self-filamentous under mating conditions, they mated and sporulated efficiently with a cells, and they were not induced to develop in the presence of other $\alpha$ cells. The expression of $S X I 1 \alpha$ in wild-type $\alpha$ cells did not have a noticeable effect on these cells. However, the expression of GPD-SXI1 $\alpha$ in a cells resulted in a striking phenotype: $\mathbf{a}+S X I 1 \alpha$ cells are selffilamentous (Fig. 7B, middle panel). These cells behave like $\mathbf{a} / \alpha$ diploid cells; on mating medium, they form filaments, basidia, and viable spores that are indistinguishable from diploid filamentation. Thus, Sxil $\alpha$ is sufficient to confer $\alpha$ identity and change an a cell into an $\mathbf{a} / \alpha$ cell.
SXI1 $\alpha$ represses $\alpha$ pheromone transcription during mating and diploid filamentation

$S X I 1 \alpha$ is an important regulator of the C. neoformans sexual cycle, and we were interested in identifying targets of $S X I 1 \alpha$. In many other fungi, the regulatory complexes that control cell identity repress the expression of haploid-specific genes such as pheromone, making this a logical target for repression by Sxil $\alpha$. To evaluate regulation of pheromone transcription by $S X I 1 \alpha$, Northern blot analysis was carried out on wild-type and $s \times i 1 \alpha \Delta$ strains under filamentation conditions. Figure 8A shows the levels of $M F \alpha$ pheromone in the different test strains. Pheromone transcript levels are very low in haploid wild-type and $s \times i 1 \alpha \Delta$ strains on filamentation medium in the absence of a mating partner (Fig. 8A, first row, lanes 5,6$)$. However, when mixed with a wild-type a mating partner, pheromone transcript levels in both wildtype and sxi1 $\alpha \Delta$ strains are greatly induced (Fig. 8A, first row, lanes 1,2 ), and the induction in the sxi1 $\alpha \Delta$ strain is much higher than in wild-type $\alpha$ cells. This increased expression of $M F \alpha$ is also observed during diploid filamentation. Wild-type a/ $\alpha$ strains produce substantially

\begin{tabular}{|c|c|c|c|c|}
\hline $\mathbf{A}$ & & Filame & Formation & \\
\hline strain & plasmid & alone on $V 8$ & $\begin{array}{l}\text { crossed with } \\
\text { wild-type a cells }\end{array}$ & $\begin{array}{l}\text { crossed with } \\
\text { wild-type } \alpha \text { cells }\end{array}$ \\
\hline wild-type & $\begin{array}{l}\text { +empty } \\
\text { vector }\end{array}$ & - & +++ & - \\
\hline & $+S X I 1 \alpha$ & - & +++ & - \\
\hline$\alpha \operatorname{sxi} 1 \alpha \Delta$ & $\begin{array}{l}\text { +empty } \\
\text { vector }\end{array}$ & - & $+/-$ & - \\
\hline & $+S X I 1 \alpha$ & - & +++ & - \\
\hline wild-type & $\begin{array}{l}\text { +empty } \\
\text { vector }\end{array}$ & - & - & +++ \\
\hline $\mathbf{a} c$ & $+S X 11 \alpha$ & ++ & + & +++ \\
\hline
\end{tabular}

Figure 7. Sxil $\alpha$ induces sexual development in a cells. $(A)$ The table summarizes the results of $S X I 1 \alpha$ overexpression in wild-type $\alpha$ cells, sxi1 $\alpha$ deletion cells, and wild-type a cells alone and during mating with a and $\alpha$ cells. (B) Panels show the results of a filamentation assay in which strains were tested for the ability to produce filaments in the absence of a mating partner. Each row contains from left to right a schematic representation of the genotype of the test strain, the strain under low magnification, and individual cells under higher magnification. The top row shows wild-type a cells; the middle row shows wild-type a cells overexpressing $S X I 1 \alpha$; and the bottom row shows wildtype $\mathbf{a} / \alpha$ diploid filamentation.
B

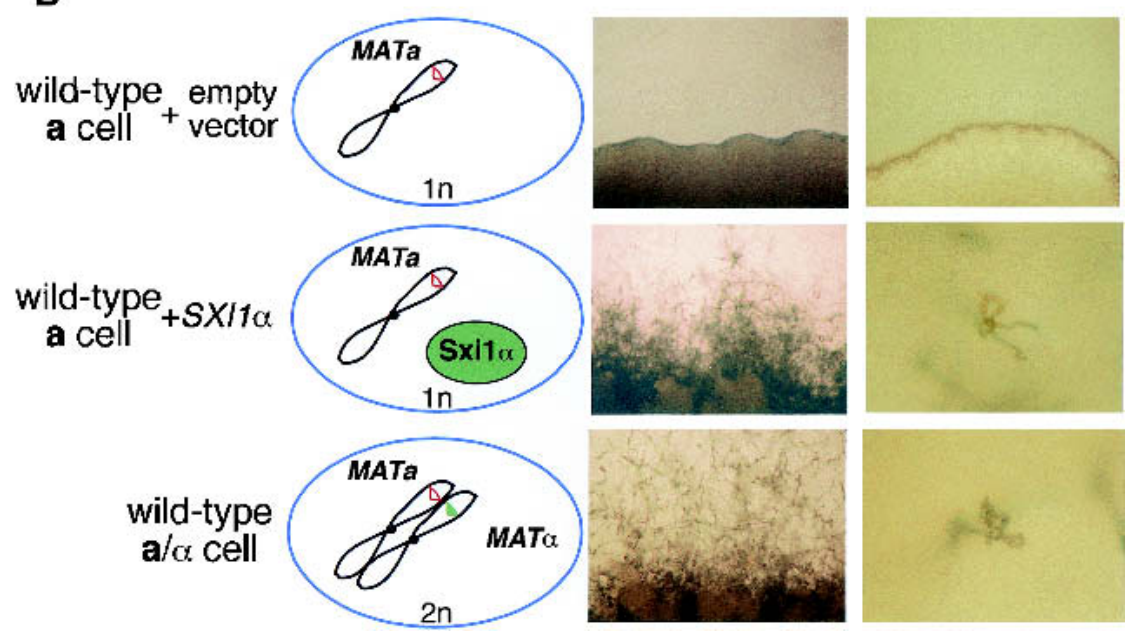




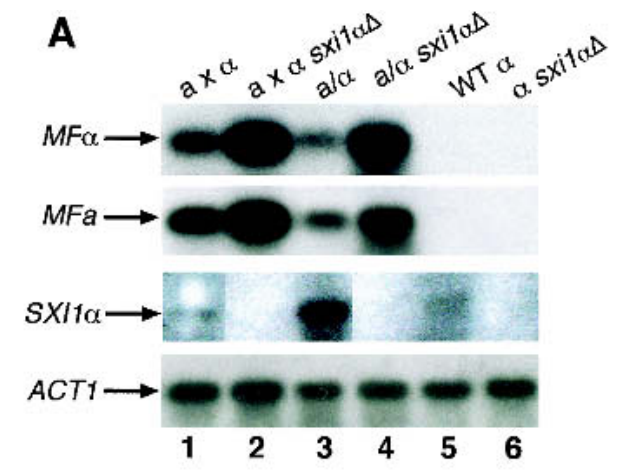

B

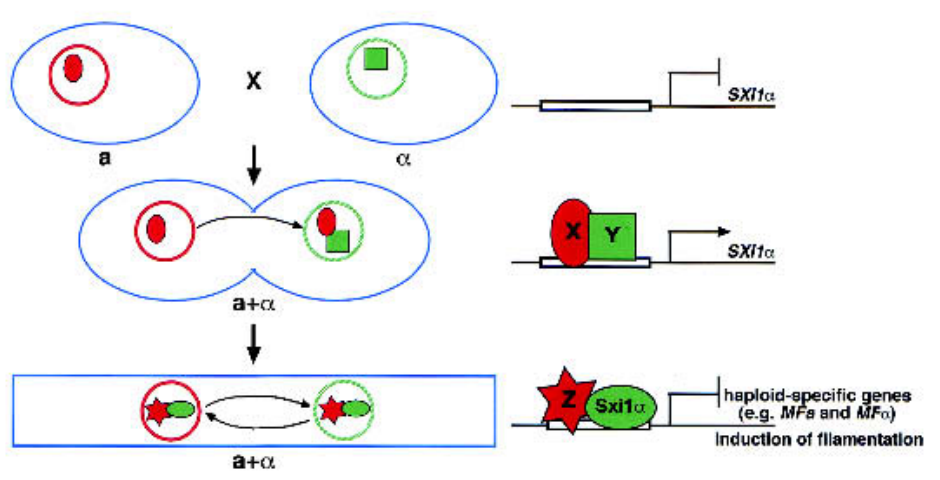

Figure 8. Sxil $\alpha$ represses pheromone gene expression. (A) A Northern blot probed with the $M F \alpha$ open reading frame (first row) shows the levels of $M F \alpha$ transcripts in wild-type and sxi1 $\alpha$ deletion strains under different conditions. The second, third, and fourth rows show the same blot probed with portions of the $M F \boldsymbol{a}, S X I 1 \alpha$, and ACT1 open reading frames, respectively. (Lane 1) Wild-type a strain cocultured with wild-type $\alpha$ strain under mating conditions; (lane 2) wild-type a strain cocultured with $\alpha$ sxi1 $\alpha \Delta$ mutant under mating conditions; (lane 3 ) wild-type a/ $\alpha$ diploid under filamentation conditions; (lane 4) a/ $\alpha$ sxi1 $\alpha \Delta$ diploid under filamentation conditions; (lane 5) wild-type $\alpha$ cells alone under mating conditions; (lane 6) $\alpha$ sxi1 $\alpha \Delta$ cells alone under mating conditions. (B) Model for the role of Sxil $\alpha$ in controlling sexual development. The blue objects represent cells. The solid, red circle represents the a nucleus, and the hatched, green circle represents the $\alpha$ nucleus. The red oval $\mathrm{X}$ and the red star $\mathrm{Z}$ represent unknown a-specific factors. The green square Y represents an unknown $\alpha$-specific factor. The green oval represents Sxil $\alpha$. (Top) SXI1 $\alpha$ is not expressed in haploid $\alpha$ cells. (Middle) Following cell fusion, SXI1 $\alpha$ expression is dependent on factors from both a and $\alpha$ cells (X and $Y$ ). (Bottom) After induction, Sxil $\alpha$ is depicted forming a heterodimeric complex with an unknown a-specific factor $\mathrm{Z}$ that establishes the dikaryotic state and induces sexual development through the repression of haploid-specific genes. more pheromone than haploid cells on filament-inducing medium, but the induction in an a/sxi1 $\alpha \Delta$ strain is even higher (Fig. 8A, first row, lanes 3,4). This expression pattern is mirrored in the pheromone transcripts from a cells as well ( $M F \mathbf{a}$; Fig. 8A, second row). Our data show increased pheromone transcript levels and are consistent with a model in which Sxil $\alpha$ represses pheromone expression after cell fusion. Perhaps high levels of pheromone after cell fusion inhibit proper filament formation, and the role of Sxil $\alpha$ is to repress pheromone levels after cell fusion to allow normal filament formation.

The expression pattern of $S X I 1 \alpha$ is consistent with this idea as well. As shown in Figure 8A /third row, lanes $5,6)$, the $S X I 1 \alpha$ transcript is not detectable in haploid cells in the absence of a mating partner or in the $s x i 1 \alpha$ deletion strain under the same conditions. However, in mating mixes of a and $\alpha$ cells, the transcript is induced in wild-type strains but is absent from sxi1 $\alpha$ deletion strains (Fig. 8A, third row, lanes 1,2 ), and in a/ $\alpha$ cells this induction in wild-type cells is even greater (Fig. 8A, third row, lanes 3,4). This suggests that a factor from a cells induces the expression of $S X I 1 \alpha$ following the fusion of a and $\alpha$ cells, and Sxil $\alpha$ can then directly or indirectly regulate pheromone genes and other as-yet-unidentified target genes.

\section{Discussion}

We have described here the discovery of a novel region of the $C$. neoformans MAT locus that encodes the cell-type regulator Sxil $\alpha$. A deletion of the previously identified $\sim 50$-kb region of the MAT $\alpha$ allele in C. neoformans had an unexpected phenotype because it did not perturb cell fate. That is, a/ $\alpha$ cell identity was not lost with the deletion of MAT $\alpha$. This result prompted us to investigate the mechanisms by which sexual differentiation is controlled. Using homozygous $\mathbf{a} / \mathbf{a}$ and $\alpha / \alpha$ diploid strains in filamentation assays, we ruled out the hypothesis that ploidy is the sole regulator of diploid filamentation and showed that both a and $\alpha$ information are necessary for sexual differentiation. This discovery led us to consider that cell-type-specific components related to those in other fungi could be responsible for directing cell identity and sexual development. We identified the homeodomain-encoding gene $S X I 1 \alpha$ and discovered that it is both necessary and sufficient for specifying $\alpha$ identity and for promoting proper development during mating and diploid filamentation. Sxil $\alpha$ is a formal repressor of the a and $\alpha$ pheromone genes, and levels of $S X I 1 \alpha$ transcript are increased after fusion with a mating partner. These data support a model in which Sxil $\alpha$ functions as a transcriptional regulator responsible for signaling cell identity and allowing progression through the sexual cycle.

\section{Sxi1 $\alpha$ acts after cell fusion}

The experiments presented here show how a single mating-type-specific protein can profoundly influence the process of sexual development. Our data provide insight 
into when and how Sxil $\alpha$ exerts its influence and lead us to propose that Sxil $\alpha$ is important for signaling the dikaryotic state (Fig. 8B). This unique time in development is one in which each cell in a filament contains two nuclei (one from a and one from $\alpha$ ) whose replication and transport into the next cell must be carefully orchestrated to maintain the process of development and allow spore formation. In this model, Sxil $\alpha$ could signal dikaryon formation after cell fusion by repressing haploidspecific genes that are no longer necessary for mating.

The idea that the primary role for Sxil $\alpha$ is after mating partners fuse is supported by several observations. First, the frequency of dikaryon formation during mating is not altered in an sxi1 $\alpha$ deletion strain, indicating that Sxil $\alpha$ is not required for signaling to a mating partner or promoting the process of cell fusion. Second, diploid strains do not filament properly in the absence of Sxil $\alpha$. Stable diploid strains have already undergone cell and nuclear fusion, and thus, the filamentation defect seen in an $\mathbf{a} / \alpha$ sxi1 $\alpha$ deletion strain must be attributable to a block after fusion. These data could be interpreted to suggest that Sxil $\alpha$ is simply an inducer of filamentation; however, this is not the case. sxila deletion strains do not have a defect in haploid fruiting. Under low-nitrogen, desiccating conditions, haploid $\alpha$ sxi1 $\alpha$ strains form filaments, basidia, and spores like wild-type $\alpha$ cells. In addition, overexpression of SXI1 $\alpha$ in $\alpha$ cells does not result in diploid filament formation as it does in a cells, indicating that the role of Sxil $\alpha$ is to mediate sexual development and not simply to induce filament formation.

\section{An a-specific factor is required for sexual development}

How Sxil $\alpha$ induces sexual development is not yet clear. The process requires Sxil $\alpha$ and at least one a-specific component, and this is reminiscent of a classic homeodomain heterodimeric complex. A well-studied example of this form of regulation is that of the a1- $\alpha 2$ heterodimer in S. cerevisiae. In this ascomycete, the al protein from a cells associates with the $\alpha 2$ protein from $\alpha$ cells to form a novel activity in diploid cells that represses haploid-specific genes and allows diploid cells to undergo meiosis and sporulation (Johnson 1995). This pattern of regulation is also seen in basidiomycetes like Ustilago maydis, where the $\mathrm{bE} 1$ and $\mathrm{bW} 1$ proteins function as a heterodimer in the diploid state to repress genes and promote sexual development (Kamper et al. 1995; Brachmann et al. 2001). Although we favor a model in which Sxil $\alpha$ forms a heterodimeric regulatory complex with an a-specific factor, the sequence of the complete MATa allele (Lengeler et al. 2002) has not revealed any strong candidates for the homeodomain, HMG box, or $\alpha$-domain proteins that are often present in the MAT loci of other fungi (Coppin et al. 1997). In fact, only a single a-specific gene, NCP1a, has been identified in the MATa sequence, and its predicted product has no similarity to any known sequence or structural motifs. Deletion of NCP1 $\boldsymbol{a}$ does not lead to a detectable mating phenotype, excluding this gene as encoding the Sxil $\alpha$ partner (C.M.
Hull, K. Forrester, and J. Heitman, unpubl.). In the absence of a clear Sxil $\alpha$ binding partner but a clear dependence of sexual differentiation on an a-specific factor, an alternate model is one in which one of the a alleles in $M A T a$ has a disparate function from its partner allele in MAT $\alpha$. The product of the a-specific allele could interact with or modify Sxil $\alpha$ to direct its function in the dikaryon.

\section{SXI1 $\alpha$ is induced during mating}

The expression pattern of $S X I 1 \alpha$ also distinguishes this cell fate determinant from its homeodomain counterparts in other fungi. Unlike many other homeodomain regulators of cell identity, SXI1 $\alpha$ is not expressed at detectable levels in haploid cells. Transcript levels are induced in a mating between a and $\alpha$ cells and are significantly induced in $\mathbf{a} / \alpha$ diploid cells. This pattern is consistent with a model in which activation of $S X I 1 \alpha$ is dependent on an a-specific factor that acts on the $S X I 1 \alpha$ gene after cell fusion (Fig. 8B, factor X). Expression of $S X I 1 \alpha$ is even higher in the diploid state because there is constitutive induction of its transcription in the diploid nucleus. The expression of $S X I 1 \alpha$ is also dependent on an additional $\alpha$-specific factor (Fig. 8B, factor Y). Because $S X I 1 \alpha$ is not expressed in a cells under the control of its own promoter, and because Sxil $\alpha$ activity is preserved in the $\mathbf{a} / \Delta$ strain, we conclude that another component from MAT $\alpha$ (that resides outside the deleted $\sim 50$-kb region) is necessary to activate $S X I 1 \alpha$.

\section{C. neoformans has an unusual MAT locus}

Although clearly classed with the basidiomycete phylum of fungi, C. neoformans is very different from its basidiomycete relatives. It is the only human pathogen in the basidiomycete phylum (although there are many plant pathogens), and it does not have the classic MAT locus architecture that has been defined for model basidiomycetes. Well-studied basidiomycetes like $U$. maydis, Coprinus cinereus, and Schizophyllum commune all have two MAT loci in which one locus encodes pheromones and pheromone receptors, and the other encodes homeodomain DNA-binding proteins (Casselton and Olesnicky 1998). This structure has not been conserved in C. neoformans. The work presented here predicts the existence of a second, linked, MAT $\alpha$ region containing SXI1 $\alpha$ or the inclusion of SXI1 $\alpha$ in a locus larger than the $\sim 50$-kb region identified previously. Recent evidence to be presented elsewhere demonstrates that the MAT locus of $C$. neoformans is in fact much larger than previously described (Lengeler et al. 2002). Large-scale BAC mapping and sequence analyses have shown that the $M A T$ locus is $\sim 105 \mathrm{~kb}$ in size, contains genes never seen before in MAT loci, and encodes pheromones, pheromone receptors, and now, the homeodomain regulatory protein, Sxil $\alpha$.

Although the C. neoformans MAT locus architecture differs from that of its basidiomycete relatives, the iden- 
tification of a homeodomain regulator of its sexual cycle is entirely consistent with established paradigms by which fungal sexual development is governed. Nearly all fungi in which a sexual cycle has been identified (and some where one has not) contain a presumptive MAT locus with regulatory proteins. In sexual fungi, homeodomain, $\alpha$-domain, and HMG-box proteins control mating, cell and nuclear fusion, meiosis, and spore formation (Coppin et al. 1997; Turgeon 1998). Thus, the absence of clear MAT DNA-binding proteins in C. neoformans had been somewhat mysterious. The classic DNA-binding proteins were not present in the known $M A T \alpha$ region, and identifying such proteins in the $C$. neoformans genome sequence had not been successful previously. No similarities between the C. neoformans genome and other fungal MAT DNA-binding proteins resulted in significant scores by BLAST search analysis.

Our approach to identify $S X I 1 \alpha$ and other putative homeodomain proteins was based on direct comparisons of sequences with weak BLAST scores with known homeodomain structural motifs. This approach enabled us to identify candidates that contain residues conserved in the DNA-binding helices of many homeodomain proteins and map well to the $S$. cerevisiae a1- $\alpha 2$ crystal structure (Li et al. 1995). Given the weak identity between fungal homeodomains and other fungal DNAbinding regulators (fungal $\alpha$-domain proteins share quite low similarity at the amino acid level), this weak primary sequence similarity was not surprising. However, a broader comparison of the predicted Sxil $\alpha$ homeodomain region with other homeodomain proteins from plants and animals resulted in a clear relationship. In fact, the Sxil $\alpha$ homeodomain is more similar to the nonfungal homeodomain protein Gsp1 from the green algae Chlamydomonas reinhardtii and the mouse homeodomain protein Meis2 than it is to those of its basidiomycete relatives $C$. cinereus and $U$. maydis.

Although many features of Sxil $\alpha$ are unique, it still belongs to a class of gene-specific regulators of cell identity that includes $S$. cerevisiae MATa1, C. reinhardtii GSP1, and the M. musculus Sry. One hallmark characteristic of all of these regulators is that they alter for establish) the identity of a cell. Expression of MATa1 in haploid $\alpha$ cells results in the repression of haploid-specific genes and creates a meiosis-competent state; expression of GSP1 in gamete cells activates the zygote developmental program; expression of Sry converts XX animals to the XY fate, and the expression of $S X I 1 \alpha$ in haploid a cells activates a diploid sexual development program. In each case the fate of the cell is dependent on the presence of a single, dominant factor that drastically alters the expression patterns of cell-type-specific genes. Discovering additional targets of Sxil $\alpha$ will reveal the extent to which transcription profiles must be altered to achieve the dikaryotic state. With the discovery of Sxil $\alpha$, we have answered the question as to whether such celltype-specific regulators exist in C. neoformans, and this advance allows us to now move on to elucidate the mechanism by which $S x i 1 \alpha$ and regulators like it establish cell fate and control sexual differentiation. The dis- covery of the central role that Sxil $\alpha$ plays in establishing cell fate also provides a molecular foundation from which to explore the known link between the $\alpha$ allele of the $M A T$ locus and virulence.

\section{Materials and methods}

\section{Constructing mat $\alpha$ and sxil $\alpha$ deletion strains}

To create the mat $\alpha$ deletion strain, a PCR overlap approach (Ho et al. 1989; Horton et al. 1989; Davidson et al. 2002) was used to make a disruption fragment. The left end of the locus was amplified with primers JOHE3186 (AGGTACGGAATCATTTCT CAT) and JOHE4439 (CCACCTCCTGGAGGCAAGATGCC TAACGACAGCCAG). The right end of the locus was amplified with primers JOHE5076 (GGATCCACTAGTTCTAGAAAC GCC) and JOHE5700 (GGTCGAGCAACTTCGCTCTGCTGT TGTGAGCGGCGT). The URA5 selectable marker was amplified with primers JOHE4440 (CTGGCTGTCGTTAGGCATCT TGCCTCCAGGAGGTGG) and JOHE5699 (ACGCCGCTCA CAACAGCAGAGCGAAGTTGCTCGACC). The amplified products were gel purified and extracted together. Primers JOHE3186 and JOHE5076 were then used in a PCR to overlap the three templates into a $4.8-\mathrm{kb}$ mat $\alpha:: U R A 5$ deletion construct containing the left and right portions of the known $M A T \alpha$ region flanking the URA5 gene. The linear disruption allele was then introduced into the serotype D ura5/ura5 diploid strain RAS008 by biolistic transformation as described by Toffaletti et al. (1993). Eighty transformants were screened by PCR for the absence of signal with STE12 $\alpha$-specific primers. Southern analysis was performed using probes for several genes in the locus (left end, STE11 $\alpha, Z N F 1 \alpha, P R T 1 \alpha$ ) to confirm the deletion in one transformant $(\mathbf{a} /$ mat $\alpha \Delta, \mathrm{RDC} 42-5)$.

Similarly, two different PCR-generated disruption constructs were created to delete most of the $S X I 1 \alpha$ open reading frame. Portions of the upstream and downstream regions of $S X I 1 \alpha$ flanking URA5 were created using the following primers: left flank, JOHE7032 (GTTGTTGCTTAAATCGATGC) and JOHE7034 (GGTCGAGCAACTTCGCTCCTAGCAAAAGTG ACTCTATTC); right flank, JOHE7035 (CCACCTCCTGGAG GCAAGCGTGTTAATACAGATAAACC) and JOHE7037 (CC ATTGGAGGAAGCTGTGGGCTG); URA5 marker, JOHE7033 (GAATAGAGTCACTTTTGCTAGGAGCGAAGTTGCTCGA CC) and JOHE7036 (GGTTTATCTGTATTAACACGCTT GCCTCCAGGAGGTGG). Portions of the upstream and downstream regions of $S X I 1 \alpha$ flanking the dominant selectable marker NAT1 were created using the following primers: left flank, JOHE7032 (GTTGTTGCTTAAATCGATGC) and JOHE7134 (CAGCTCACATCCTCGCAGCCTAGCAAAAG TGACTCTATTC); right flank, JOHE7070 (САTCTCTTCTA TAAGCTTCGTGTTAATACAGATAAACC) and JOHE7037 (CCATTGGAGGAAGCTGTGGGCTG); NAT1 marker, JOHE7068 (GAATAGAGTCACTTTTGCTAGGCTGCGAGG ATGTGAGCTG) and JOHE7071 (GGTTTATCTGTATTAA CACGAAGCTTATAGAAGAGATG). The sxi1 $\alpha:: U R A 5$ PCRgenerated overlap fragment was transformed using biolistic transformation into the ura5 haploid strain JEC34 and the ura5/ ura5 diploid strain RAS009. Recovered transformants were screened by PCR and Southern blots and resulted in the haploid and diploid deletion strains CHY610 and CHY615. The sxi1 $\alpha:$ NAT1 PCR fragment was transformed into the previously constructed and characterized mata deletion strain RDC42-5 to create the mat $\alpha \Delta$ sxi1 $\alpha \Delta$ diploid strain CHY625. Transformations were carried out by biolistics on YPD plates containing $1 \mathrm{M}$ sorbitol. Transformants were allowed to recover 
at $30^{\circ} \mathrm{C}$ for $4-6 \mathrm{~h}$, scraped off the transformation plates, and plated on YPD plates containing $100 \mu \mathrm{g} / \mathrm{mL}$ nourseothricin.

\section{PCR amplification}

All PCR amplifications were performed using the ExTaq PCR system (Intergen). Primers were used at a concentration of 0.5 $\mu \mathrm{M}$, and templates for PCR reactions were titrated and evaluated empirically for each product. PCR overlap conditions used were as described previously (Davidson et al. 2002). For diagnostic PCR to distinguish $\mathbf{a} / \mathbf{a}$ and $\alpha / \alpha$ cells, primers to the STE2Oa and STE20 $\alpha$ genes were used as in Sia et al. (2000) on genomic DNA templates. PCR to confirm the mata deletion strain was carried out with the following primer sets, and a subset of these primers was also used to generate probes used in Southern and Northern analysis: control primers to the CPK1 gene, JOHE1703 (AAGGATCCATATGACAATCGACCAAA GCCAAATC) and JOHE1704 (AACTGCAGGCACCTCATCG TAAATCATTCCT); primers A, JOHE3186 (AGGTACGGAAT CATTTCTCAT); B, JOHE5548 (GCAGGAAACTCCCCT TCT); C, JOHE6332 (TGGATCATGACGATCGGACAC); D, JOHE5910 (CAACTATGTGGCAACAACATGG); STE12 $\alpha$, JOHE4545 (ACAACCTGGCTTAGAAGA) and JOHE4546 (CC TCTCGAAACCATTTCT); STE20 $\alpha$, JOHE3069 (GATTTATC TCAGCAGCCACG) and JOHE3070 (AAATCGGCTACGG GACGTC); STE11 $\alpha$, JOHE5306 (GGTCGAGCAACTTCGCT CATTTACAGGGCTGTCCTG) and JOHE5391 (GCTCGT TCTCCCCTGTAC); $M F \alpha$, JOHE1204 (TTTTACGCTTTTTG CAGATTCCGCCAAA) and JOHE3242 (GACCACTGTTT CTTTCGTTCT); MFa, JOHE6683 (TTCTTCGGCAGCCTCA CTAT) and JOHE6684 (GAAAAGAGGTACGAGTAGAT); ACT1, JOHE6307 (CTGTCTTCCCTTCTATTGTTGGTCG) and JOHE6308 (CACTGTACTTTCGCTCGGGAGG). Primers to the $S X I 1 \alpha$ gene used to show $\alpha$-specific segregation and to generate a probe for Southern and chromoblot hybridizations were JOHE6510 (CGTCCGTCTCTGGTTTCTTG) and JOHE6511 (GGCGATAATTAGTCAGATCA).

\section{Strain manipulations and media}

All strains used were of the serotype D background and are described in the relevant procedures. All were handled using standard techniques and media as described by Alspaugh et al. (1997) and Guthrie and Fink (1991). Mating and self-filamentation assays were conducted on V8 medium at room temperature in the dark for 2-5 d. Filamentation was evaluated by observing the periphery of test spots on V8 medium. The mating tester strains used were JEC20 (a) and JEC21 $(\alpha)$. Diploid strains were all prototrophic, with the exception of the a/0 strain (RDC42-5). This strain was created by selecting against the URA5 gene on 5 -FOA, which led to either the loss of the $\alpha$ chromosome creating a $2 n-1$ strain, or a mitotic cross-over event, resulting in a functional a/a strain. The $\mathbf{a} / 0$ strain was tested for filamentation on V8 medium supplemented with uracil.

\section{Assisted mating reactions}

Matings to create $\mathbf{a} / \mathbf{a}$ and $\alpha / \alpha$ homozygous diploid strains were carried out as follows: For a/a strains, JEC171 (a ade2 lys2) and JEC53 (a ura5 lys1) were grown on YPD medium and resuspended in water in approximately equal amounts with (assisted mating) and without (unassisted mating) JEC157 ( $\alpha$ ura5 ade2 lys1). For $\alpha / \alpha$ strains, JEC170 ( $\alpha$ ade2 lys2) and JEC52 ( $\alpha$ ura5 lys1) were grown on YPD medium and resuspended in water in approximately equal amounts with and without JEC169 (a ade2 ura5 lys1). Mixtures were spotted onto V8 medium and incu- bated in the dark at room temperature for 4-7 d. Mating mixes were then scraped off the V8 medium; resuspended in water; plated to selective plates lacking uracil, adenine, and lysine; and grown at $30^{\circ} \mathrm{C}$ for $3 \mathrm{~d}$. No prototrophs were recovered from the unassisted mating mixes. Prototrophs from the assisted mating were tested for DNA content by FACS. FACS analysis was carried out according to Sia et al. (2000). The control $\alpha$ haploid strain was JEC21. The control a/ $\alpha$ diploid strain was RAS009. Test strains were a/a CHY600 and $\alpha / \alpha$ CHY601. Positive diploid strains by FACS were tested for a and $\alpha$ information by PCR (see PCR section).

\section{Ectopic expression experiments}

The predicted SXI1 $\alpha$ ORF was generated via PCR using primers JOHE8206 (CGAGGATCCATGCTTTCGACCTGTGAT) and JOHE8523 (CGGGATCCCTTTAGTTTAAGTCGGGGATCA) and a cloned genomic fragment as template. The resulting PCR product was cloned and sequenced to verify a wild-type clone (pCH254). The SXI1 $\alpha$ ORF was liberated from pCH254 with BamHI, and cloned into the BamHI site of the telomeric, GPD1containing plasmid pRCD85 to create pCH258. pCH258 was digested with the meganuclease I-SceI to expose its telomeric ends and then transformed by electroporation into JEC34 (a ura5), JEC43 ( $\alpha$ ura5), and CHY618 ( $\alpha$ sxi1 $\alpha:: N A T 1$ ura5) to create the strains CHY656, CHY657, and CHY658, respectively. pCH258 was also transformed into a 5-FOA-resistant derivative of CHY625 $(\mathbf{a} / \Delta s x i 1 \alpha \Delta)$ and found to restore filamentation behavior to that of the a/ $\Delta$ strain RDC42-5. SXI11 $\alpha$ overexpression strains were evaluated for self-filamentation and mating on V8 plates at room temperature for $2-5 \mathrm{~d}$ in the dark.

\section{Southern blot analysis}

Genomic DNA was isolated from strains using the method of Pitkin et al. (1996). Twenty micrograms of genomic DNA was digested with the indicated enzymes and electrophoresed on $0.8 \%$ TBE agarose gels. Transfer, hybridization, and autoradiography were performed as previously described (Ausubel et al. 1992) and by using the Alk-Phos Direct Detection System (Amersham Pharmacia Biotech). PCR-generated fragments were used as probes for Southern blot hybridizations: left end, JOHE3186 (AGGTACGGAATCATTTCTCAT) and JOHE4439 (CCACCTCCTGGAGGCAAGATGCCTAACGA CAGCCAG); $P R T 1 \alpha$, JOHE6526 (AAATCTTCCATCGGTC TCAG) and JOHE6527 (ACAATTCCTCAGTCTCATCG); ZNF1 $\alpha$, JOHE6149 (CTTTTGCCCTCGTACTCCGCACC) and JOHE6150 (CCGGATTGCCATGCACAGGACGC); see PCR section for remaining primer sequences. Chromoblot was a gift from Klaus Lengeler (Duke University, Durham, NC) and was hybridized in parallel under the same conditions as the Southern blots.

\section{Northern blot analysis}

RNA was prepared from C. neoformans cells using a hot phenol extraction protocol for S. cerevisiae (Ausubel et al. 1992). Northern blots were carried out according to standard protocols (Ausubel et al. 1992) with $10 \mu \mathrm{g}$ of total RNA used for each sample. The $M F \alpha, M F a, S X I 1 \alpha$, and ACT1 probes were generated by PCR as described in the PCR section, and radiolabeled probes (Rediprime II kit from Amersham Pharmacia Biotech) were used in hybridization reactions as described previously (Church and Gilbert 1984 ) at $65^{\circ} \mathrm{C}$.

\section{Sequence manipulations}

Sequence comparisons were conducted using the BLAST algorithm (Altschul et al. 1997) against the Stanford C. neoformans 
genome sequence [version 5, C. neoformans Genome Project, Stanford Genome Technology Center (http://www-sequence. stanford.edu/group/C.neoformans/index.html), funded by the NIAID/NIH under cooperative agreement U01 AI47087, and The Institute for Genomic Research, funded by the NIAID/NIH under cooperative agreement U01 AI48594]. Sequence analyses were conducted and phylogenetic trees and alignments were generated using SeqWeb Version 2 (Accelrys). Sequence alignment was displayed using SeqVu Version 1.1 (The Garvan Institute of Medical Research). The SXI1 $\alpha$ sequence can be obtained from GenBank using accession no. AY162324.

\section{Acknowledgments}

The authors thank R. Brazas, R. Wharton, D. Lew, B. Capel, and J. McCusker for helpful comments and discussions; M.-J. Boily, K. Forrester, and C. Arndt for technical assistance; and other members of the Heitman Laboratory, especially K. Lengeler, for their support. This work was supported by an NIAID RO1 grant AI50113 to J.H. and an NIAID program project grant AI44975 to the Duke University Mycology Research Unit. C.M.H. is supported by a Damon Runyon Cancer Research Fund Fellowship, DRG-1694. J.H. is a Burroughs-Wellcome Scholar in Molecular Pathogenic Mycology and an Associate Investigator of the Howard Hughes Medical Institute.

The publication costs of this article were defrayed in part by payment of page charges. This article must therefore be hereby marked "advertisement" in accordance with 18 USC section 1734 solely to indicate this fact.

\section{References}

Alspaugh, J.A., Perfect, J.R., and Heitman, J. 1997. Cryptococcus neoformans mating and virulence are regulated by the Gprotein $\alpha$ subunit GPA1 and cAMP. Genes \& Dev. 11: 32063217.

Alspaugh, J.A., Davidson, R.C., and Heitman, J. 2000. Morphogenesis of Cryptococcus neoformans. Contrib. Microbiol. 5: 217-238.

Altschul, S.F., Madden, T.L., Schaffer, A.A., Zhang, J., Zhang, Z., Miller, W., and Lipman, D.J. 1997. Gapped BLAST and PSI-BLAST: A new generation of protein database search programs. Nucleic Acids Res. 25: 3389-3402.

Ausubel, F.M., Brent, R., Kingston, R.E., Moore, D.D., Seidman, J.G., Smith, J.A., and Struhl, K., eds. 1992. Current protocols in molecular biology. Greene Publishing Associates and Wiley-Interscience, New York.

Banuett, F. and Herskowitz, I. 1989. Different $a$ alleles of Ustilago maydis are necessary for maintenance of filamentous growth but not for meiosis. Proc. Natl. Acad. Sci. 86: 58785882.

Brachmann, A., Weinzierl, G., Kamper, J., and Kahmann, R. 2001. Identification of genes in the $\mathrm{bW} / \mathrm{bE}$ regulatory cascade in Ustilago maydis. Mol. Microbiol. 42: 1047-1063.

Burglin, T.R. 1997. Analysis of TALE superclass homeobox genes (MEIS, PBC, KNOX, Iroquois, TGIF) reveals a novel domain conserved between plants and animals. Nucleic Acids Res. 25: 4173-4180.

Capel, B. 1998. Sex in the 90s: SRY and the switch to the male pathway. Annu. Rev. Physiol. 60: 497-523.

Casadevall, C. and Perfect, J.R. 1998. Cryptococcus neoformans, 1st ed. ASM Press, Washington, DC.
Casselton, L.A. and Olesnicky, N.S. 1998. Molecular genetics of mating recognition in basidiomycete fungi. Microbiol. Mol. Biol. Rev. 62: 55-70.

Chang, Y.C., Wickes, B.L., Miller, G.F., Penoyer, L.A., and Kwon-Chung, K.J. 2000. Cryptococcus neoformans STE12 $\alpha$ regulates virulence but is not essential for mating. J. Exp. Med. 191: 871-882.

Church, G.M. and Gilbert, W. 1984. Genomic sequencing. Proc. Natl. Acad. Sci. 81: 1991-1995.

Clarke, D.L., Woodlee, G.L., McClelland, C.M., Seymour, T.S., and Wickes, B.L. 2001. The Cryptococcus neoformans $S T E 11 \alpha$ gene is similar to other fungal mitogen-activated protein kinase kinase kinase (MAPKKK) genes but is mating type specific. Mol. Microbiol. 40: 200-213.

Coppin, E., Debuchy, R., Arnaise, S., and Picard, M. 1997. Mating types and sexual development in filamentous ascomycetes. Microbiol. Mol. Biol. Rev. 61: 411-428.

Davidson, R.C., Moore, T.D., Odom, A.R., and Heitman, J. 2000. Characterization of the $M F \alpha$ pheromone of the human fungal pathogen Cryptococcus neoformans. Mol. Microbiol. 38: 1017-1026.

Davidson, R.C., Blankenship, J.R, Kraus, P.R., de Jesus-Berrios, M., Hull, C.M., D'Souza, C., Wang, P., and Heitman, J. 2002. A PCR-based strategy to generate integrative targeting alleles with large regions of homology. Microbiology 148: 26072615.

Guthrie, C. and Fink, G.R. 1991. Guide to yeast genetics and molecular biology. Academic Press, San Diego.

Haqq, C.M. and Donahoe, P.K. 1998. Regulation of sexual dimorphism in mammals. Physiol. Rev. 78: 1-33.

Hartwell, L.H. 1980. Mutants of Saccharomyces cerevisiae unresponsive to cell division control by polypeptide mating hormone. J. Cell Biol. 85: 811-822.

Herskowitz, I., Rine, J., and Strathern, J. 1992. Mating-type determination and mating-type interconversion in Saccharomyces cerevisiae. In Molecular and cellular biology of the yeast Saccharomyces: Gene Expression (eds. E.W. Jones et al.), pp. 583-656. Cold Spring Harbor Laboratory Press, Cold Spring Harbor, NY.

Ho, S.N., Hunt, H.D., Horton, R.M., Pullen, J.K., and Pease, L.R. 1989. Site-directed mutagenesis by overlap extension using the polymerase chain reaction. Gene 77: 51-59.

Horton, R.M., Hunt, H.D., Ho, S.N., Pullen, J.K., and Pease, L.R. 1989. Engineering hybrid genes without the use of restriction enzymes: Gene splicing by overlap extension. Gene 77: 61-68.

Hull, C.M. and Johnson, A.D. 1999. Identification of a mating type-like locus in the asexual pathogenic yeast Candida albicans. Science 285: 1271-1275.

Johnson, A.D. 1995. Molecular mechanisms of cell-type determination in budding yeast. Curr. Opin. Genet. Dev. 5: 552558.

Kamper, J., Reichmann, M., Romeis, T., Bolker, M., and Kahmann, R. 1995. Multiallelic recognition: Nonself-dependent dimerization of the $\mathrm{bE}$ and $\mathrm{bW}$ homeodomain proteins in Ustilago maydis. Cell 81: 73-83.

Karos, M., Chang, Y.C., McClelland, C.M., Clarke, D.L., Fu, J., Wickes, B.L., and Kwon-Chung, K.J. 2000. Mapping of the Cryptococcus neoformans MAT $\alpha$ locus: Presence of mating type-specific mitogen-activated protein kinase cascade homologs. J. Bacteriol. 182: 6222-6227.

Kronstad, J.W. and Staben, C. 1997. Mating type in filamentous fungi. Annu. Rev. Genet. 31: 245-276.

Kwon-Chung, K.J., Edman, J.C., and Wickes, B.L. 1992. Genetic association of mating types and virulence in Cryptococcus neoformans. Infect. Immun. 60: 602-605. 
Hull et al.

Lengeler, K.B., Davidson, R.C., D'Souza, C., Harashima, T., Shen, W.C., Wang, P., Pan, X., Waugh, M., and Heitman, J. 2000. Signal transduction cascades regulating fungal development and virulence. Microbiol. Mol. Biol. Rev. 64: 746785.

Lengeler, K.B., Fox, D.S., Fraser, J.A., Allen, A., Forrester, K., Dietrich, F.S., and Heitman, J. 2002. Mating type locus of Cryptococcus neoformans: A step in evolution of sex chromosomes. Eukaryot. Cell 1: 704-718.

Li, T., Stark, M.R., Johnson, A.D., and Wolberger, C. 1995. Crystal structure of the MATa1/MAT $\alpha 2$ homeodomain heterodimer bound to DNA. Science 270: 262-269.

Moore, T.D. and Edman, J.C. 1993. The $\alpha$-mating type locus of Cryptococcus neoformans contains a peptide pheromone gene. Mol. Cell. Biol. 13: 1962-1970.

Parkhurst, S.M. and Meneely, P.M. 1994. Sex determination and dosage compensation: Lessons from flies and worms. Science 264: 924-932.

Pitkin, J.W., Panaccione, D.G., and Walton, J.D. 1996. A putative cyclic peptide efflux pump encoded by the TOXA gene of the plant-pathogenic fungus Cochliobolus carbonum. Microbiology 142: 1557-1565.

Sia, R.A., Lengeler, K.B., and Heitman, J. 2000. Diploid strains of the pathogenic basidiomycete Cryptococcus neoformans are thermally dimorphic. Fungal Genet. Biol. 29: 153-163.

Toffaletti, D.L., Rude, T.H., Johnston, S.A., Durack, D.T., and Perfect, J.R. 1993. Gene transfer in Cryptococcus neoformans by use of biolistic delivery of DNA. I. Bacteriol. 175: $1405-1411$.

Turgeon, B.G. 1998. Application of mating type gene technology to problems in fungal biology. Annu. Rev. Phytopathol. 36: $115-137$.

Wickes, B.L., Mayorga, M.E., Edman, U., and Edman, J.C. 1996 Dimorphism and haploid fruiting in Cryptococcus neoformans: Association with the $\alpha$-mating type. Proc. Natl. Acad. Sci. 93: 7327-7331.

Yue, C., Cavallo, L.M., Alspaugh, J.A., Wang, P., Cox, G.M., Perfect, J.R., and Heitman, J. 1999. The STE12 $\alpha$ homolog is required for haploid filamentation but largely dispensable for mating and virulence in Cryptococcus neoformans. Genetics 153: $1601-1615$.

Zhao, H., Lu, M., Singh, R., and Snell, W.J. 2001. Ectopic expression of a Chlamydomonas $\mathrm{mt}^{+}$-specific homeodomain protein in $\mathrm{mt}^{-}$gametes initiates zygote development without gamete fusion. Genes \& Dev. 15: 2767-2777. 


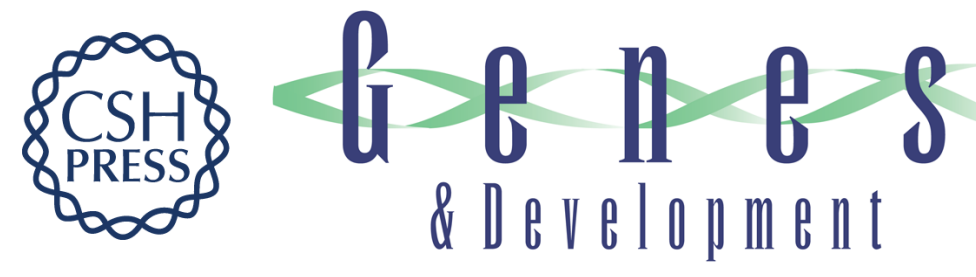

\section{Cell identity and sexual development in Cryptococcus neoformans are controlled by the mating-type-specific homeodomain protein Sxi1 $\alpha$}

Christina M. Hull, Robert C. Davidson and Joseph Heitman

Genes Dev. 2002, 16:

Access the most recent version at doi:10.1101/gad.1041402

References This article cites 36 articles, 19 of which can be accessed free at:

http://genesdev.cshlp.org/content/16/23/3046.full.html\#ref-list-1

License

Email Alerting Receive free email alerts when new articles cite this article - sign up in the box at the top Service right corner of the article or click here.

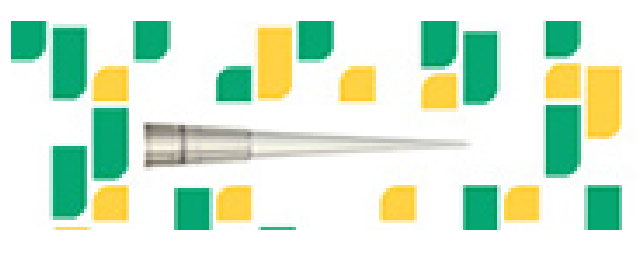

Focused on your science. 